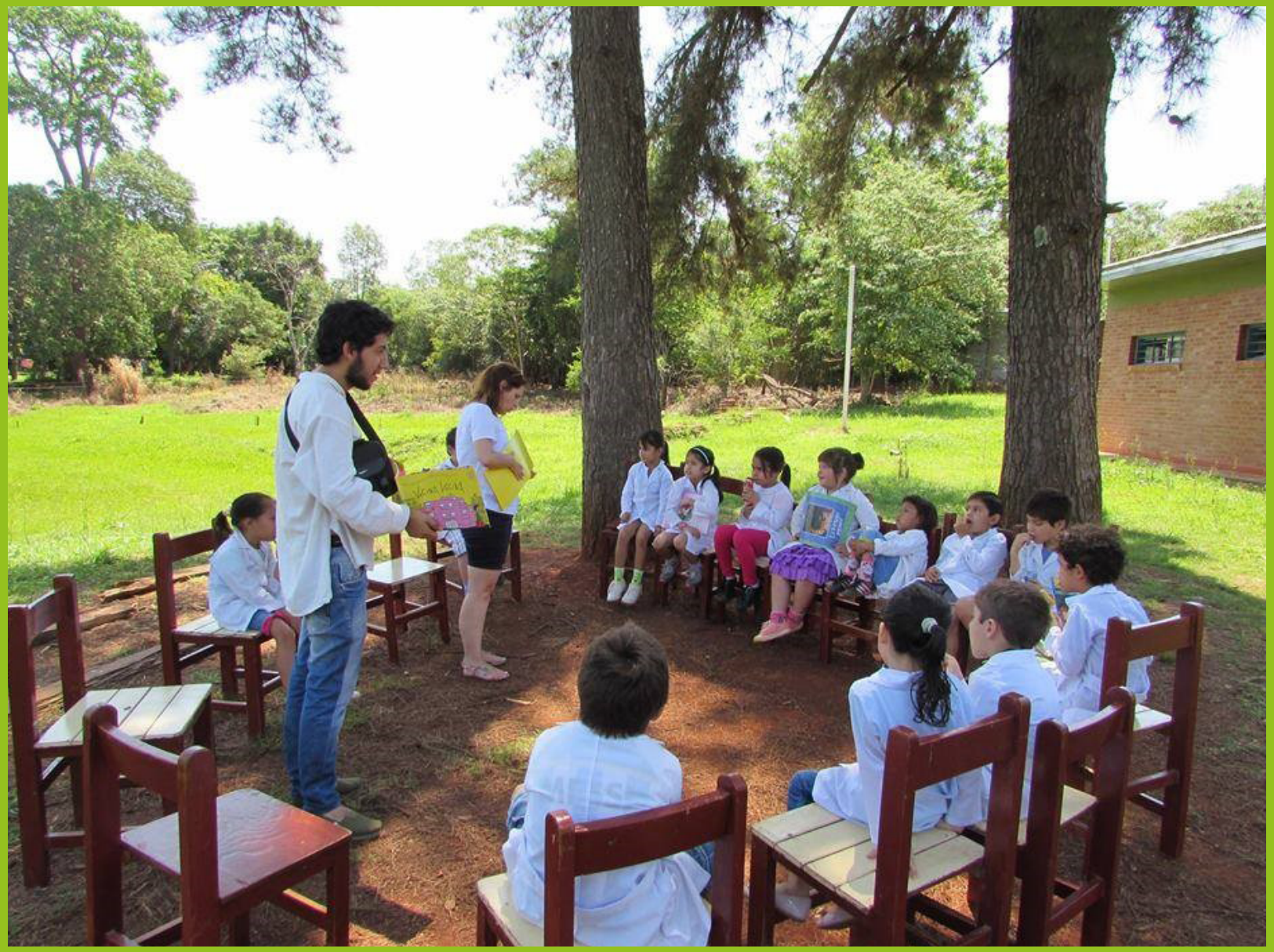

\title{
Leitura e escrita em espaços coletivos: primeiros passos da ação
}

Mariana Cortez

mariana.cortez@unila.edu.br ${ }^{1}$

Edwin Alexander Sanabria Ospina

edwinsanabria91@gmail ${ }^{2}$ 
O projeto de extensão "Vivendo livros latino-americanos na tríplice fronteira: descobrir e resgatar identidades" trabalha nas bibliotecas das escolas públicas da região da tríplice fronteira (Ciudad del Este, Foz do Iguaçu e Puerto Iguazú) com o propósito de contribuir para a reflexão de professores e alunos no que concerne às práticas de leitura e escrita que se desenvolvem nesses espaços coletivos, à formação de professores e à situação do espaço físico e ao acervo necessário para a promoção da leitura e escrita literária, de forma a integrá-la à dinâmica escolar como ambiente essencial aos processos de aprendizagem. 0 projeto interessase especialmente por contribuir para a consolidação de acervos referentes à literatura latino-americana, bem como propor práticas pedagógicas que valorizem a leitura e a escrita literária como um processo de visibilidade das identidades da fronteira.

Palavras-chave: Fronteira. Biblioteca escolar. Acervo. Interculturalidade ráfica.

\section{ABSTRACT}

The extension project "Vivendo livros latino-americanos na tríplice fronteira: descobrir e resgatar identidades", works on libraries of the public schools locales on the triple border region (Puerto Iguazú, Foz do Iguaçu and Ciudad del Este), with the purpose of contributing to the reflection of teachers and students. Regarding the reading and writing practices that take place in these collective spaces, where the teacher training, the physical space situation and the collection are necessary for the promotion of literary reading and writing, which is part of the school dynamics and essential environment for learning processes. Therefore we emphasize especially the amount of Latin American literary works that are found in the schools of the border region and at the same time propose pedagogical practices that value literary reading and writing, which serve as visibility process of border identities.

Keywords: Border. School library. Collection. Interculturality.

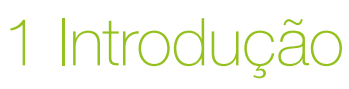

0 projeto de extensão "Vivendo livros latino-americanos na tríplice fronteira: descobrir e resgatar identidades tem como proposta trabalhar nas bibliotecas das escolas públicas da região da tríplice fronteira (Brasil, Argentina e Paraguai), conforme imagem esboçada na Figura 1, com o propósito de contribuir para a reflexão de professores e alunos no que concerne às práticas de leitura e escrita que se desenvolvem nesses espaços coletivos, à formação de professores e à situação do espaço físico e ao acervo necessário para a promoção da leitura e escrita literária, de forma a integrá-la à dinâmica escolar como ambiente essencial aos processos de aprendizagem e de disseminação de Cultura e Artes na América Latina.

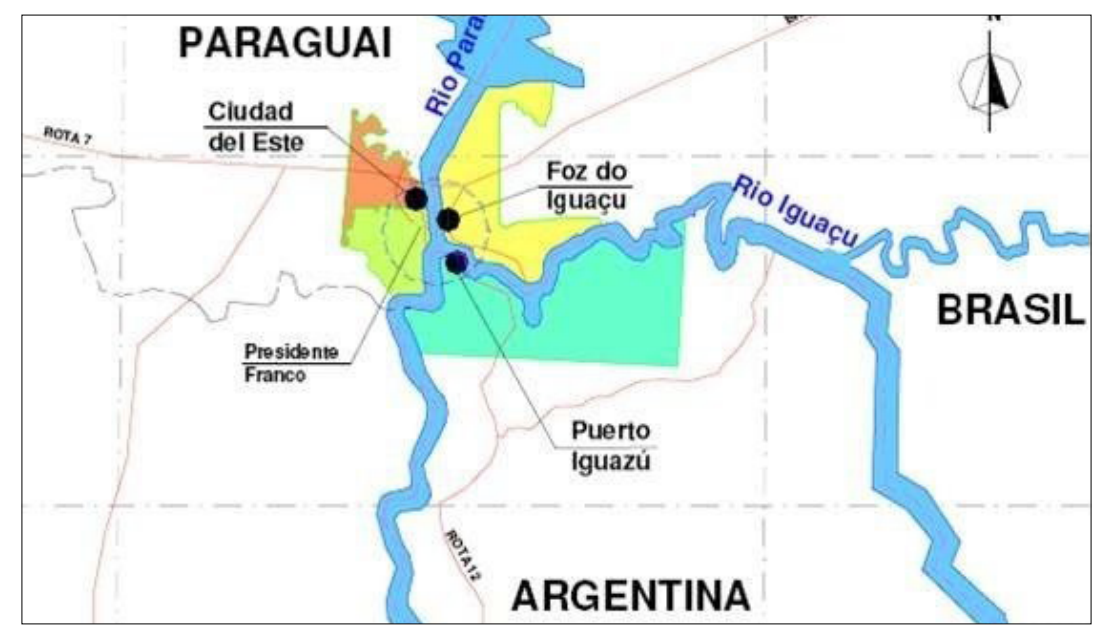

Figura 1: Mapa região de tríplice fronteira

Fonte: https://mapasblog.blogspot.com/2011/07/mapas-de-puerto-iguazu-argentina.html (consulta: 10/7/2019) 
O projeto se propôs a trabalhar, especificamente, na Escola Municipal Brigadeiro Antonio Sampaio (Foz do Iguaçu) e Escuela 722, Eduardo Arrabal (Puerto Iguazú) com o intuito de estruturar e organizar o espaço físico, catalogar o acervo de obras e propor práticas de leitura e escrita, problematizando a visibilidade das identidades dos sujeitos de fronteira. Ao longo da descrição, faremos referências aos procedimentos, metodologias e referencial teórico utilizado, para poder delinear os desafios e avanços encontrados durante essa etapa de trabalho. Apresentaremos com maior profundidade os resultados alcançados na Escola Municipal do Campo Brigadeiro Antonio Sampaio, Foz do Iguaçu.

\section{Metodologia}

A execução do projeto "Vivendo livros latino-americanos na tríplice fronteira" foi iniciada com o mapeamento das escolas nas cidades da fronteira. Nesta etapa, visitamos 8 escolas: 4 em Foz do Iguaçu e 4 em Puerto Iguazú. Em cada uma das escolas coletamos um registro fotográfico e entrevistas com os docentes do ensino fundamental dos anos iniciais .

As escolas escolhidas para visitação e aplicação das entrevistas foram aquelas indicadas pelos supervisores de ensino (Brasil /Argentina) como as mais carenciadas, no que diz respeito às bibliotecas e às atividades com leitura e escrita. Os docentes foram escolhidos pela própria direção da escola. Em todas as escolas visitadas, realizamos duas entrevistas.

Elaboramos um roteiro de entrevista semiestruturada que, dependendo da situação que observamos na escola, sofreu algumas alterações para que a conversa entre o entrevistador e o entrevistado pudesse ser mais natural e fluida. Todas as entrevistas foram realizadas pelos alunos extensionistas (do terceiro e quarto ano do Curso de Antropologia da Unila) e, no desenrolar do projeto, tais estudantes foram também apropriando-se do roteiro. Assim é possível avaliar positivamente a estratégia de uma entrevista mais flexível, resultando, portanto, em uma coleta qualitativa e não quantitativa, como era nosso objetivo inicial.

Já o registro fotográfico compreendeu os espaços destinados aos livros (biblioteca escolar, cantinho de leitura, caixa de livros, estantes e mobiliários etc.) e também o acervo de obras, que, por vezes, surpreendeu pela presença de exemplares da América Latina em geral. Nas análises dos registros fotográficos, algumas vezes recorremos às entrevistas dos docentes para estabelecer o diálogo entre o que diz o professor e a situação registrada. 0 período de coleta de dados compreendeu um mês do trabalho de campo para, em seguida, produzirmos um relatório com os dados coletados e apresentá-los para os docentes e diretores das escolas que participam do projeto.

No ano de 2016, trabalhamos na terceira fase de nosso projeto, na qual foi empregado o seguinte cronograma: primeiramente, para os meses de abril a julho, trabalhar na Escola Municipal do Campo Brigadeiro Antonio de Sampaio, em Foz do Iguaçu. Nesta etapa, fizemos a catalogação e tabulação dos dados referentes ao acervo bibliográfico da escola e também elaboramos um desenho do espaço físico para a criação da biblioteca escolar (Figura 2). Este espaço foi pensado a partir das necessidades da escola e suas possibilidades de estrutura física.

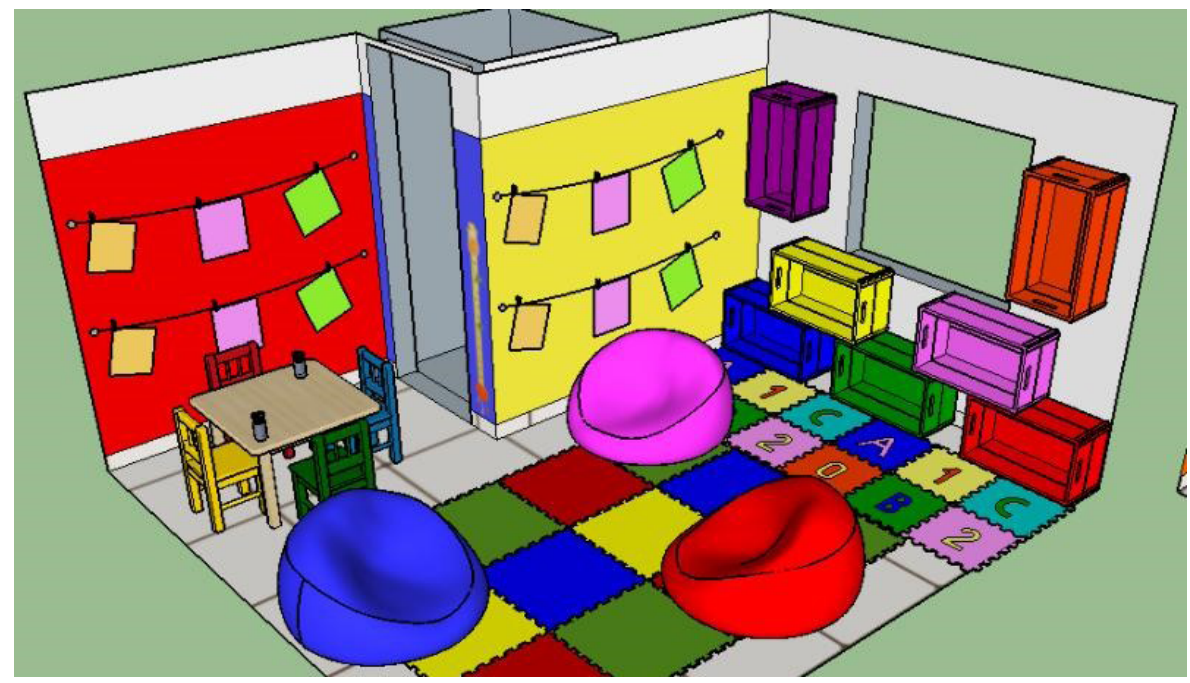

Figura 2: Biblioteca da Escola Municipal do Campo Brigadeiro Antonio de Sampaio Fonte: Acervo do projeto. 
Para cumprir esse objetivo, executamos o seguinte planejamento: i) organização e catalogação das obras numa planilha eletrônica e posteriormente no software PHL; ii) elaboração do projeto do espaço físico da biblioteca, de acordo com o espaço da escola e conforme as especificações do público participante, nos quais aspectos culturais, pedagógicos e de acessibilidade vão ser eixos fundamentais para o prosseguimento do projeto; iii) por último, fizemos uma análise dos dados, de acordo com os critérios propostos na fase de catalogação e tabulação.

Esse mesmo procedimento foi executado na Escola Rural 722 - Eduardo Horacio Arrabal, em Puerto Iguazú, Argentina. No entanto, o presente artigo terá como objetivo apresentar o desenvolvimento da experiência de pesquisa-ação na escola brasileira.

\section{Fundamentação Teórica}

Entendemos ser fundamental, nas bibliotecas das escolas públicas, a disponibilização de textos dos mais variados gêneros: livros de contos, romances, poesia, enciclopédias, dicionários, jornais, revistas (infantis, em quadrinhos, de palavras cruzadas e outros jogos), livros de consulta das diversas áreas do conhecimento, almanaques, revistas de Literatura de Cordel, textos gravados em áudio e em vídeo, entre outros. Mas, sobretudo, seria importante promover a cultura de ler e escrever: "a biblioteca da escola deve ser promotora da cultura mais que um complemento didático" (PETIT, 2009, p.269).

Enfatizamos que nos interessa, com a execução desse projeto de extensão, especialmente contribuir para uma consolidação de acervos referentes à literatura latino-americana, bem como propor práticas pedagógicas que valorizem a leitura e a escrita literária como um processo de descoberta e resgate das identidades da fronteira, cumprindo assim também os objetivos de um projeto de extensão que visa ao enlace entre a universidade e a sua comunidade.

Maria Aparecida Bezerra (2008), reconhecida pesquisadora na área das bibliotecas escolares, indica que "o processo de ensino e aprendizagem supõe uma dinâmica de atos que ocorrem para a formação de hábitos e habilidades que o educando vai adquirindo no decorrer de sua vida escolar. Logo, a biblioteca passa a ser um recurso imprescindivel” (BEZERRA, 2008, p. 5).

Segundo esta perspectiva, podemos afirmar que as bibliotecas são lugares decisivos nas trajetórias de vida das pessoas, pois contribuem no fortalecimento das suas habilidades como cidadãos. No caso da região da tríplice fronteira, há a presença de diferentes culturas no espaço escolar. Essa diversidade, porém, muitas vezes sofre um apagamento em detrimento de uma dada cultura hegemônica, que, de certa forma, impera nos espaços educacionais, materiais didáticos e mesmo na literatura que circula na escola. Por meio de atividade já realizada nas escolas em Puerto Iguazú e Foz do Iguaçu, foi possível perceber a necessidade do diálogo intercultural nos termos propostos por Walsh (1999, p. 133):

"Lo inter es lo que Homi Bhaba refiere como el espacio intermedio o el 'tercer espacio' donde dos o más culturas se encuentran, un espacio de traducción y negociación en el cual cada una mantiene algo de sí, sin asimilarse a la otra. Esta noción del tercer espacio es útil para entender las relaciones entre interculturalidad e identidad, y unidad y diversidad, porque permite una forma de conceptualizar y visualizar la relación entre culturas como algo fluido, movible y dialéctico, como también ambivalente, contradictorio y conflictivo; sugiere, igualmente, que no hay fronteras rígidas entre culturas o entre personas que pertenecen a distintos grupos culturales como que tampoco hay culturas puras o estáticas, sino divisiones dinámicas y flexibles en las cuales siempre hay huellas o vestigios de los 'otros' en nosotros mismos".

\section{Resultados}

Como resultados de nossa proposta, ao longo do período de desenvolvimento do projeto, que começou no segundo semestre de 2014, pudemos alcançar os seguintes resultados que serão descritos em forma de itens:

a) mapeamos as escolas públicas e suas respectivas bibliotecas, no que se refere à quantidade e qualidade do acervo de obras latino-americanas, buscando entender as práticas pedagógicas realizadas na promoção da leitura nessas bibliotecas por meio de questionários analisados e tabulados;

b) selecionamos duas escolas para serem "pilotos" de nossa proposta, são elas: Escola Municipal do Campo Brigadeiro Antonio Sampaio (Foz do Iguaçu) e Escuela 722 - Eduardo Horacio Arrabal (Puerto Iguazú). A escolha das escolas se justifica graças à localização (escolas em espaços rurais) e necessidades em relação 
à formação de professores em práticas de leitura e escrita, identificadas no mapeamento anterior;

c) iniciamos o trabalho com reconhecimento e organização do acervo, além de propor experiências e reflexões sobre as práticas leitoras a professores e alunos das escolas públicas trabalhadas;

e) propusemos duas reuniões de trabalhos com os docentes das escolas selecionadas pelo projeto;

f) trabalhamos em atividades interculturais com os alunos das séries iniciais nas escolas que participam das atividades, cujos registros encontram-se nas Figuras 3 e 4 ;

g) catalogamos e organizamos o acervo já existente na Escola Municipal Brigadeiro Antonio de Sampaio, em Foz do Iguaçu.

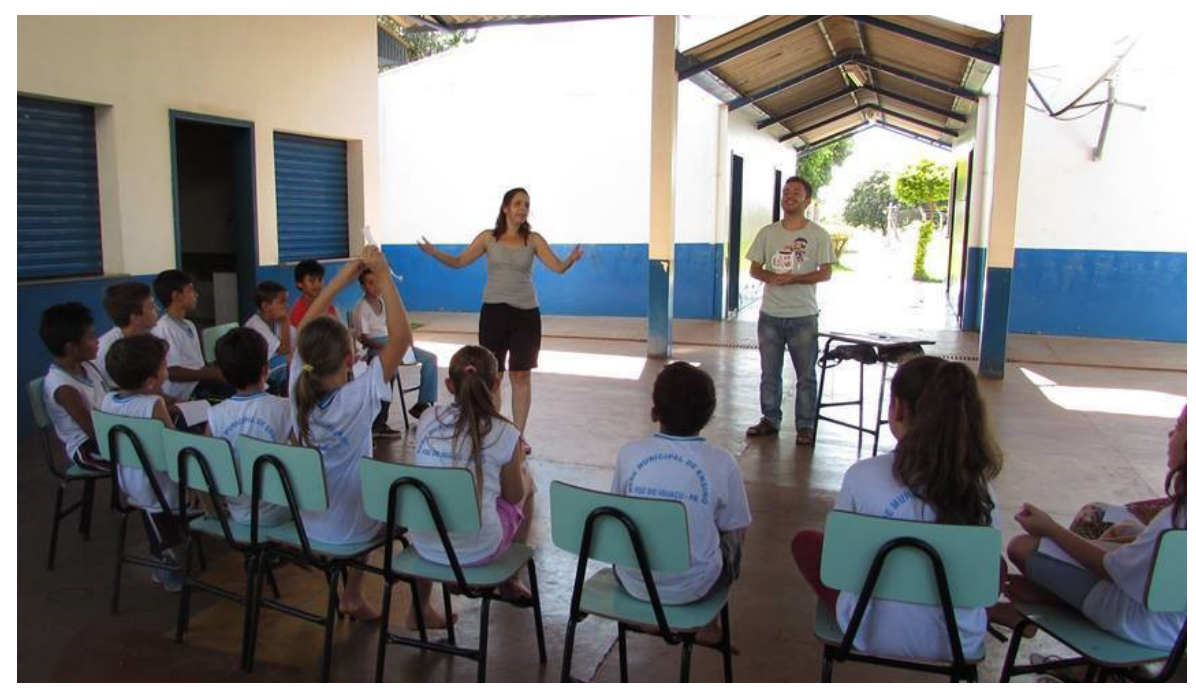

Figura 3: Trabalho na escola Brigadeiro Antonio de Sampaio Fonte: Acervo do projeto

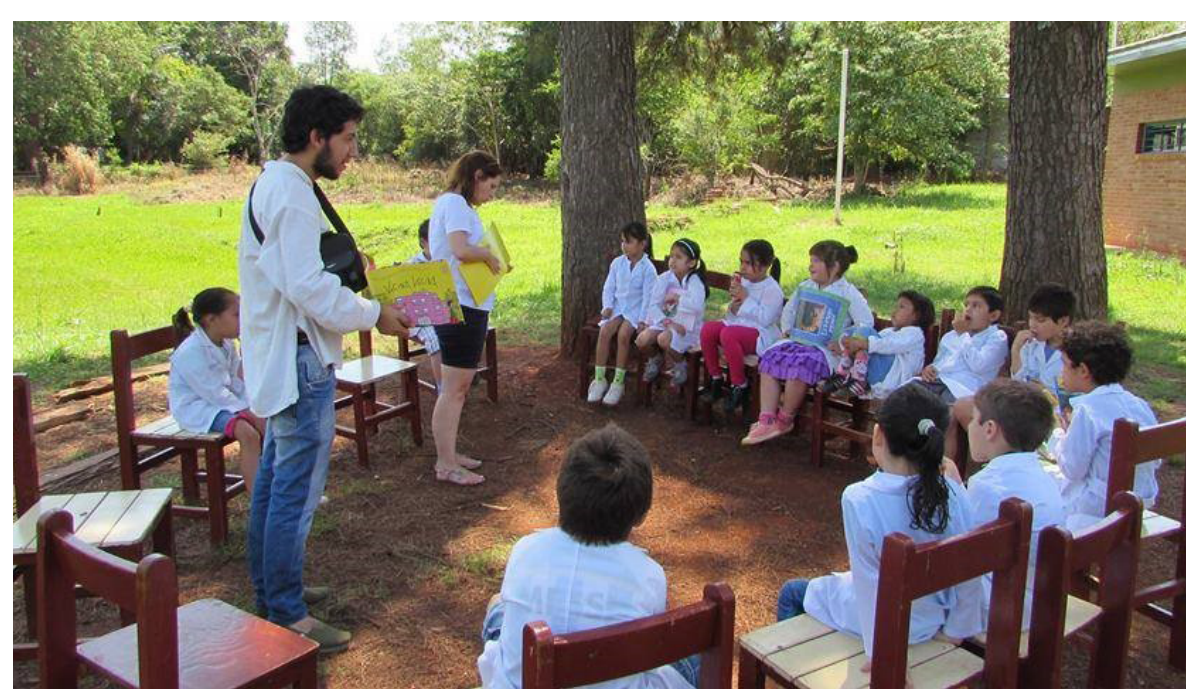

Figura 4: Atividades na escola Eduardo Arrabal 722, Argentina

Fonte: Acervo do projeto

Por meio das etapas descritas, destacam-se a seguir alguns impactos na percepção de docentes e discentes no início dos trabalhos. Os dados apresentados se referem, especificamente, à Escola Municipal do Campo Brigadeiro Antonio Sampaio :

\section{Histórico da escola e a caracterização de seus usuários}

A Escola Municipal "Brigadeiro Antonio Sampaio" está localizada na Zona rural do Município de Foz do Iguaçu, em situação limite com o município de Santa Terezinha de Itaipu, no Estado do Paraná, Brasil. Pertence ao Programa "Escolas de Campo", já que se caracteriza por ser de pequeno porte e estar mais distante do centro urbano de Foz do Iguaçu. 
A Escola foi criada com o nome de Escola Municipal "São Sebastião" e construída graças à reivindicação dos moradores da localidade, com filhos em idade escolar, que não tinham condições de frequentar a escola mais próxima, no município de Santa Terezinha de Itaipu, a $15 \mathrm{~km}$ de distância. A estrutura inicial era de madeira e contava com 1 sala de aula, 1 cozinha e patente no pátio da escola.

Com a construção da Hidrelétrica de Itaipu Binacional, a escola que se encontrava na reserva à margem do lago de Itaipu, foi transferida para o Bairro Alto da Boa Vista, autorizada a funcionar como Escola Rural Municipal "Brigadeiro Antonio Sampaio", em 1982, ainda com uma construção de madeira, 1 sala de aula, 1 cozinha e 2 banheiros de alvenaria. Funcionou até o primeiro semestre de 2004 com 57 alunos, após essa data passou-se a utilizar um novo prédio (agora localizado ao lado da vila rural): todo em alvenaria, com 2 salas de aula, 5 banheiros ( 3 utilizados pelos alunos sendo um para cadeirante), 1 cozinha, 1 dispensa, 1 sala de informática, 1 almoxarifado, 1 sala de professores e um saguão coberto atendendo uma média de 30 alunos do 1음 ao 5 ano do ensino fundamental. Atualmente, a escola tem em torno de 45 alunos nos turnos matutino e vespertino. As salas de aula são multisseriadas e, para cada uma das classes, há uma professora responsável.

Nas entrevistas, as professoras caracterizam os alunos com relação à profissão dos pais e responsáveis e suas origens da seguinte maneira: 1$)$ "não, são paraguaios mesmo que vieram aqui, eles trabalham de chacareiros né, nas chácaras assim, cuidam das chácaras"; 2) "(Os pais) trabalham lá (Centro da Cidade de Foz), são pedreiro, carpinteiro, a maioria deles, e os pais que ficam aqui ficam cuidando a chácara, a mãe né, os pais sai (sic) para trabalhar, a mãe fica com os filhos e no caso esses paraguaios vêm trabalhar aqui para cuidar das chácaras né, então eles vieram do Paraguai mesmo, mas a gente tem outro caso ali que é brasiguaio mesmo, que os pais são brasileiros mesmo, moravam no Paraguai, e acho que a criança até nasceu no Paraguai"; 3) "a nossa escola também tem muita transferência de aluno, porque assim: pessoal vem, não se dá bem no trabalho aí vai, principalmente essas pessoas que vêm trabalhar nas chácaras né, então trabalham um tempo e vão embora, aí vem outra família no lugar, é assim, então sempre tá uma mudança, sempre tem aluno chegando, tem aluno indo, tem isso bastante aqui também".

Por meio da descrição da escola, é possível enumerar as características que seguem: o seu isolamento em uma zona agrícola de monocultivo em estações alternadas entre a soja e o milho - as chácaras e agricultura familiar, a baixa renda da comunidade local aliada às condições de trabalho que geram instabilidade e, portanto, mobilidade constante entre os países que compõem a região de fronteira e o consequente intercâmbio cultural daqueles que frequentam a escola.

Além disso, as docentes relatam a dificuldade diante do isolamento da escola e uma de suas demandas foi para que o Projeto atuasse como uma forma de "sala de recursos" no contraturno escolar, pois, como as referidas docentes expõem, o deslocamento das crianças até a cidade é inviável devido à distância do centro.

Tendo em vista essa demanda, passamos a atuar na escola nos seguintes eixos: 1) remodelação da biblioteca escolar entendida como espaço profícuo (e com características que fogem à estruturação escolar) para a mediação da leitura literária e da expressão escrita; 2) proposição de práticas de mediação de leitura com estudantes do $2^{\circ}$ ao 50 ano, uma vez por semana (quarta-feira) e 3) práticas de mediação de leitura com vistas a identificar as dificuldades de aprendizagem de um grupo de 7 alunos que foram assim caracterizados pela docente responsável. Tais atividades foram propostas no contraturno escolar, também uma vez por semana.

Os resultados obtidos nos eixos foram:

1)A Biblioteca "Valeria Mancio Campos" foi inaugurada (Figura 2) e tornou-se um espaço organizado, com o acervo de obras exposto e catalogado, como se demonstrará a seguir;

2)As práticas de leitura e escrita com os alunos do 20 ao 50 ano foram avaliadas pelos discentes, docentes e equipe do projeto como bastante significativa em duas perspectivas: aproximação e familiarização dos estudantes com a biblioteca e com a leitura literária, já não apenas como leitura para ser feita quando as atividades escolares fossem terminadas (função identificada nos cantinhos de leitura - entretenimento nos momentos de pausa de atividades com "conteúdo") e autonomia das crianças com relação à expressão e voz nas conversas literárias realizadas, estes dados foram coletados por meio de relatos etnográficos realizados ao logo das interações entre a universidade e a escola (sociedade);

3)Com o grupo de estudantes identificados com dificuldades de aprendizagem, a proximidade e atenção cuidada a um grupo reduzido de estudantes propiciou a troca de experiências mediadas pela literatura e foi possível perceber e desenvolver o compromisso das crianças com sua aprendizagem e especialmente identificar o "desejo de ler", bastante destacado por elas. Foi possível, portanto, pensar na leitura literária como um espaço para o acolhimento de alunos "excluídos" do processo de aprendizagem e proporcionar formas de inclusão. 


\section{Apresentação e análise crítica dos dados do acervo}

Como uma das etapas a serem cumpridas pelo projeto, o acervo já existente na Escola Municipal do Campo "Brigadeiro Antonio Sampaio" foi catalogado e organizado. A partir desse trabalho, foi possível reconhecer que a escola possui um acervo de qualidade e vasto se for considerado o número de alunos. 0 total de obras é 752, sendo o total de títulos de 559. No entanto, esse material bibliográfico não estava acessível ou reconhecido pelos professores e alunos. Além disso, um dos aspectos de debilidade do acervo é a ausência de obras que reflitam a diversidade cultural da região de fronteira. Mais precisamente, foram catalogados 16 títulos que fazem referência aos povos originários e obras sobre a origem dos latinoamericanos e traduzidas ao português foram registradas 5, sendo 3 da Argentina, 1 do Paraguai e 1 do Chile. Os gráficos que seguem confirmam as afirmações, como demonstram as Tabelas 1 e 2 . Assim, as análises dos dados coletados indicam:

1) Grande diversidade de origem das obras, como demonstra o Figura 1. Vale destacar que, entre as obras tabuladas como latino-americanas, estão as brasileiras, como pode ser verificado no Gráfico 1;

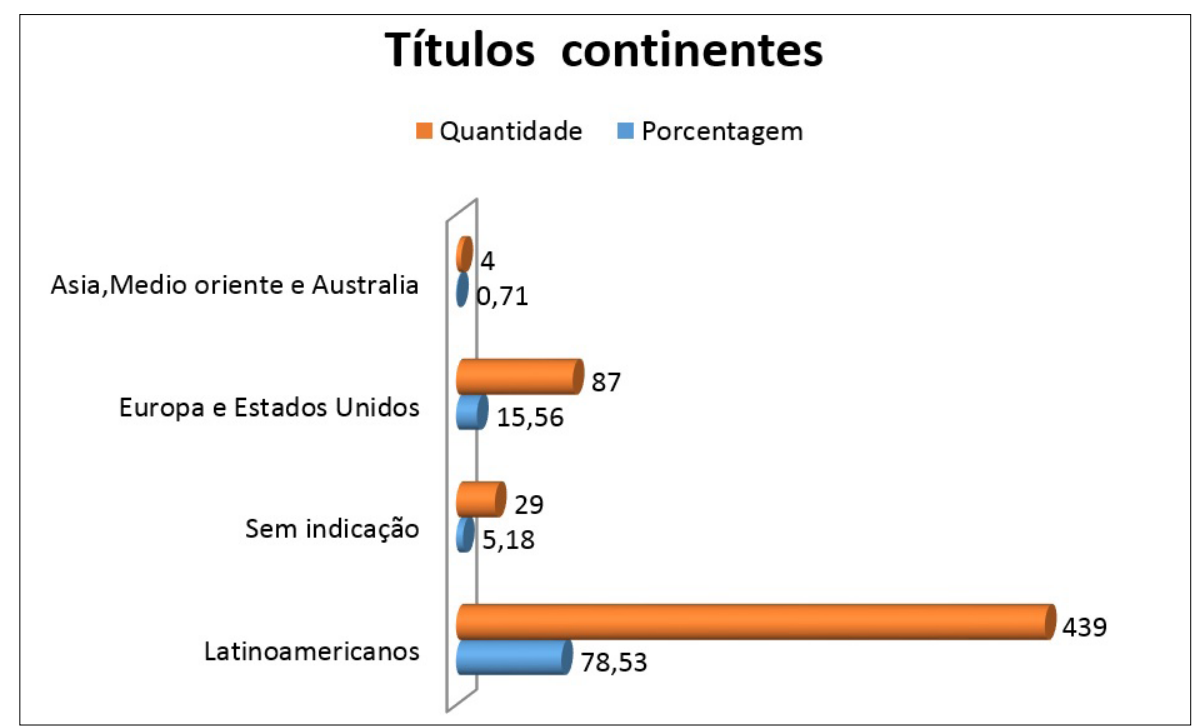

Figura 1: Títulos continentes

Fonte: Dados da pesquisa

2) Reforça-se que o acervo da escola é predominantemente composto por títulos brasileiros, como demonstra o Figura 2.

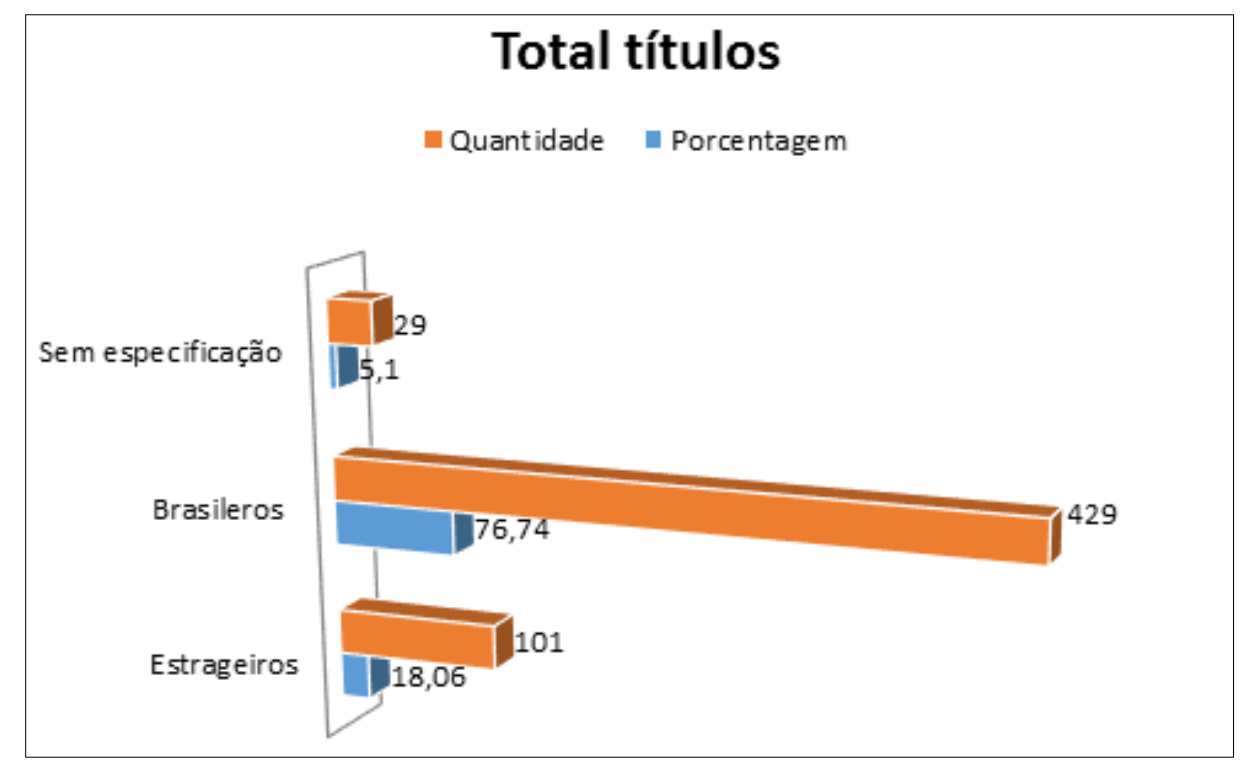

Figura 2: Total títulos

Fonte: Dados da pesquisa 
3) Há diversidade de gêneros literários como contos, crônicas, poemas, romances etc., como demonstra o Figura 3;

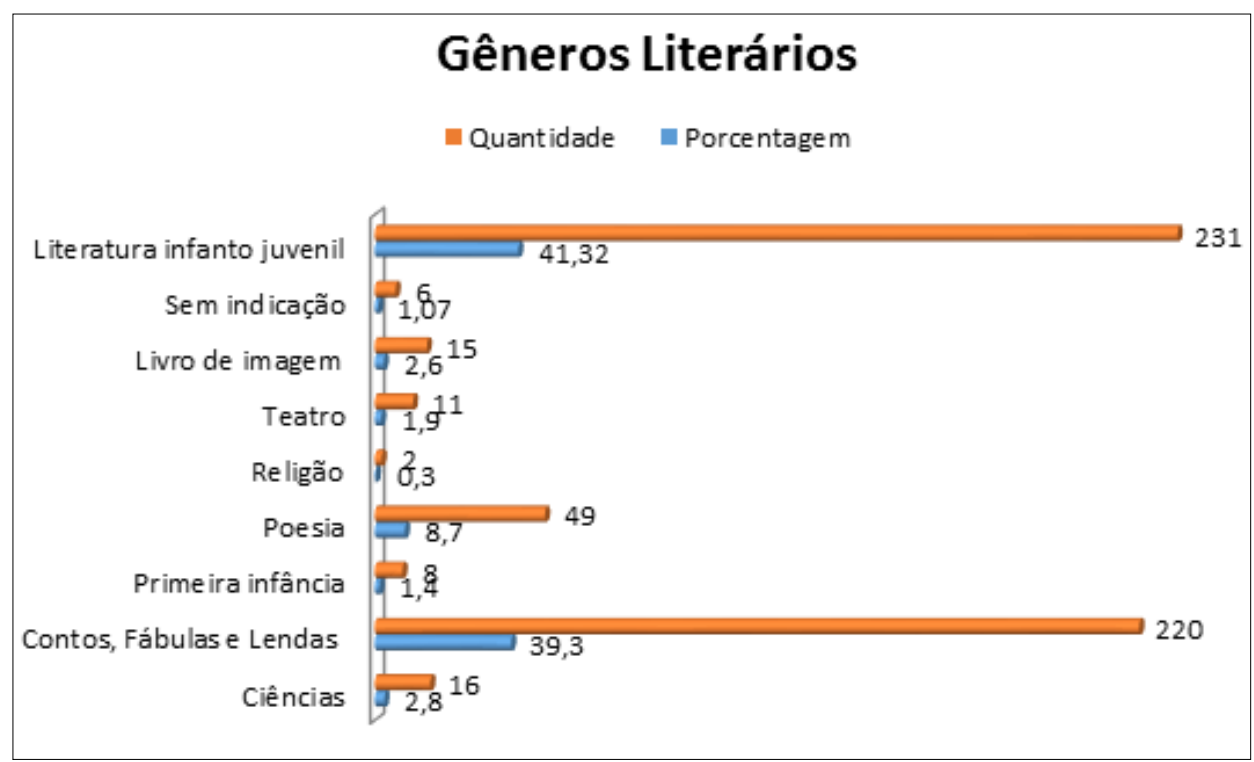

Figura 3: Gêneros Literários

Fonte: Dados da pesquisa

Assim, esclarece-se que o acervo da escola é predominantemente composto por obras distribuídas pelo Ministério da Educação Brasileiro (MEC) e pelo Ministério da Cultura (MINC), por meio dos Projetos Plano Nacional do Livro e da Leitura (PNLL) e Pacto Nacional de Alfabetização na Idade Certa, pelo Programa Nacional Biblioteca da Escola (PNBE) (MEC) , o que implica uma excelente seleção de obras - clássicas, contemporâneas, de diferentes nacionalidades, bastante diversas em relação às temáticas abordadas, qualidade do material gráfico etc. Porém, essas "caixas" oferecidas pelo MEC não levam em conta as regiões e suas características, em especial, a complexidade dos habitantes de uma fronteira pluricultural. Também, vale pontuar que pouco se capacitam os docentes para o trabalho com os livros. Em cada caixa, vem um manual de como utilizar as obras nas aulas e, muitas vezes, essas são as únicas indicações que os professores têm.

Como forma de responder aos problemas identificados, a equipe entendeu como necessárias as seguintes ações:

1) expor o acervo e dividir as obras por gêneros identificados (contos, poesia, teatro, livro de imagens etc.) e por conseguinte propor práticas de reconhecimento do espaço e da coleção.

Aos poucos, estudantes e docentes aproximam-se do espaço destinado aos livros. Identificamos que as crianças transitam com mais naturalidade no espaço; já os docentes relatam a importância da biblioteca, mas não viabilizam atividades no espaço e algumas vezes "reconstroem" os cantinhos de leitura com o objetivo de entreter as crianças nos momentos de pausa;

2) a equipe do projeto ofereceu um curso de atualização para os docentes das três escolas participantes, mas apenas um representante da escola brasileira esteve presente durante as 20 horas de curso; e

3) a participação dos estudantes nas práticas de leitura no espaço da biblioteca escolar demonstra a apropriação do espaço e muitos desejavam que fosse possível o empréstimo das obras para leituras em casa. Este aspecto ainda não foi viabilizado.

\section{Impactos nos estudantes bolsistas e voluntários}

Ao longo dos anos de desenvolvimento do projeto, foi possível contar com a participação de, ao menos, 7 estudantes de graduação (bolsistas da universidade, da Fundação Araucária e voluntários). Eles puderam planejar e executar atividades como: mediação de leitura literária nas escolas de Foz do Iguaçu e Puerto Iguazú, vale destacar que tal tarefa exigiu do extensionista habilidades linguísticas: Português para hispanofalantes e Espanhol para lusofalantes; com ajuda de voluntário externo, bibliotecário, os estudantes desenvolveram um sistema eficiente de catalogação dos acervos literários das escolas; também as propostas de leitura realizada nas escolas dos anos iniciais oportunizaram um ambiente interdisciplinar e interculturalmente sensível, já que as atividades envolviam educação, literatura, contatos linguísticos- 
culturais, biblioteconomia, entre outros. Ademais, como os estudantes eram advindos de diferentes cursos de graduação (Antropologia, Saúde Coletiva, Letras), gerou-se um espaço de troca de saberes na resolução de diversas questões surgidas durante o processo.

Posto isso, os impactos gerados são identificados tanto no que se refere ao compromisso social assumido pelos estudantes, como na formação acadêmica dos extensionistas: participação em diversos eventos de extensão (SERUS, SIEPE/UNILA, SEU/UNIOESTE etc.), publicação de 5 artigos com os resultados do projeto e continuidade de estudos: dos estudantes egressos, um deles defendeu dissertação de mestrado intitulada: "Ausências ou presenças ausentes?: os povos indígenas nos livros didáticos de Foz do Iguaçu", Daniel Gordillo Sanchéz, na Universidade Federal de Santa Catarina, e hoje exerce a profissão de coordenador pedagógico em escola pública do Estado da Paraíba, e outro voltou ao seu país de origem, Colômbia, onde trabalha com traduções e prepara seu projeto de mestrado, que também pretende que seja continuidade das reflexões realizadas durante a participação no projeto aqui relatado.

\section{Considerações finais}

A partir das observações e dados coletados, a proposta será aprofundar as atividades de discussão com os docentes e propor práticas de leitura e escrita, inserindo propostas de recuperação da identidade da fronteira e latino-americana, pois acreditamos que a literatura cumpre um papel importante no processo de socialização e transmissão dos valores culturais de um dado país, região ou mesmo comunidade. Entender a literatura como mediadora do resgate cultural da fronteira e, consequentemente, problematizar a identidade latino-americana pode ser um exercício bastante fértil para um continente que tem objetivos de integração e também para a Unila como instituição que tem a proposta de integração.

A leitura e a escrita implicam a produção e construção de sentidos, de "espaço de liberdade" (PETIT, 2001) e construção ou (re)construção da própria subjetividade: "Leer o recurrir a bienes culturales diversos, para encontrase a si mismo, para reconocerse, para construirse o reconstruirse, no es la misma experiencia que leer para olvidar o para distraerse" (PETIT, 2001, p. 109)

Nesse processo, o sujeito se forma como leitor em interação com o texto, com outros textos, com os outros em geral, a partir da sua própria história de leitor e de suas experiências de vida. Considera-se, então, que o acesso aos bens culturais é fundamental para o processo de se tornar sujeito, ao mesmo tempo em que é essencial, para isso, realizar um tipo de trabalho com a leitura e a escrita que possibilitem refletir sobre essas relações, sobre os sentidos apreendidos no texto e sobre os sentidos construídos e reconstruídos por esses sujeitos. Na região da tríplice fronteira Argentina, Brasil e Paraguai há um cruzamento e um trânsito de culturas que convergem nos espaços escolares, tal diversidade será o tema principal das práticas de leitura e escrita com vistas a resgatar as origens dos educandos e de suas famílias e quem sabe também de outros sujeitos que habitam o ambiente escolar.

\section{Referências}

BEZERRA, Maria Aparecida da Costa. $\mathbf{O}$ papel da biblioteca escolar: importância do setor no contexto educacional. CRB-8 Digital, [online]. São Paulo, v. 1, n. 2, p. 4-10, out. Disponible en: http://revista.crb8.org.br/ index.php/crb8digital/article/viewFile/24/24. 2008.

CANCLINI, Néstor García. Culturas Híbridas: estratégias para entrar e sair da modernidade. Tradução de Ana Regina Lessa e Heloísa Pezza Cintrão. 4. ed. São Paulo: EDUSP. 282 p. 2003.

ORGANIZAÇÃO DAS NAÇÕES UNIDAS. Declaração de Lyon sobre o acesso à informação e desenvolvimento. Lyon: ONU, 2014. Disponível em https://www.lyondeclaration.org/content/pages/lyon-declaration-pt.pdf: . Acesso em: 11 dez. 2019.

PETIT, Michèle. A arte de ler como resistir à adversidade; tradução de Arthur Bueno e Camila Boldrini. São Paulo: Ed. 34, 269 p. 2009.

Lecturas del espacio intimo al espacio publico ; traduccion Miguel Paleo, Malou Paleo, Diana Luz Sánchez, Bosques del pedregal:168p, 2001.

WALSH, Catherine. "La interculturalidad en el Ecuador: visión, principio y estrategia indígena para un nuevo país". FLACSO, 1999, n.20 